\title{
Editorial
}

Dermatology

\section{Ectodermal Dysplasia: Thoughts and Practical Concepts Concerning Disease Classification - The Role of Functional Pathways in the Molecular Genetic Diagnosis}

\author{
Peter $\mathrm{H}$. Itin \\ Department of Dermatology, University Hospital Basel, Basel, Switzerland
}

\begin{abstract}
Key Words
Ectodermal dysplasia $\cdot$ Signaling criteria $\cdot$ Molecular genetics
\end{abstract}

Genetic diseases involving ectodermal systems result from a disturbance in the complex development of the skin and its appendages as well as other ectodermal structures. Ectodermal dysplasias describe a large and complex group of disorders characterized by abnormal formation of the skin, its appendages (hair, nails, teeth, sweat glands and sebaceous glands) and other organs which develop from ectoderm such as the nervous system, tooth enamel, the lens of the eye and the mammary glands. They involve various organs developing from the primordial external germ layer. They may occur in isolation or in association with other more complex clinical manifestations involving the mesoderm and endoderm. Most syndromic forms of ectodermal dysplasias are recognized by particular clinical features [1]. In this issue, Yin et al. [2] described a deletion mutation in exon 8 of the EDA (ectodysplasinA) gene as a cause for X-linked hyphidrotic ectodermal dysplasia. Hypohidrotic ectodermal dysplasia can develop from different mutations belonging to the TNF- $\alpha$-like signaling pathway. Numerous mutations in the EDA gene have been reported, but EDA1R (ectodysplasin-1 receptor) or EDARADD (ectodysplasin-A receptor-associated adapter protein) defects are rarer and mutations in
TRAF6 (TNF receptor-associated factor 6) or impairment of ubiquitin binding are scarce. Rather common mutations of NEMO (NF- $\mathrm{BB}$ essential modulator) are described in patients with hypohidrotic ectodermal dysplasia accompanied by immunodeficiency and incontinentia pigmenti [3]. Recent investigations showed increasingly that ectodermal dysplasias result from related defective molecular pathways. The aim of a new planed nosology and classification is to give pediatricians, dermatologists, geneticists, ophthalmologists and otorhinolaryngologists a table of genetic disorders involving the ectoderm which can help with the diagnosis, estimation of prognosis, work-up and therapy in individual patients, the delineation of new diseases and the building of bridges between clinicians and scientists [4].

As more than 200 different ectodermal dysplasias exist, there is a remarkable overlapping of syndromic phenotypes. By 2008, 62 clinically different ectodermal dysplasias had already had a gene or a chromosome region assigned to them, and this number continues to rise [5]. Unfortunately, besides the syndrome-associated findings, patients often have other solitary nonsyndromic abnormalities, so that straightforward diagnosis can be difficult. In addition, de novo genetic mutations will continuously produce new ectodermal diseases [6]. New technologies such as genome-wide association studies and array-comparative genomic hybridization as well as whole-exome and genome sequencing have started the

\section{KARGER}

E-Mail karger@karger.com

www.karger.com/drm
(C) 2013 S. Karger AG, Basel

$1018-8665 / 13 / 2262-0111 \$ 38.00 / 0$
Peter H. Itin

Department of Dermatology, University Hospital Basel

Petersgraben 4

$\mathrm{CH}-4031$ Basel (Switzerland)

E-Mail peter.itin@unibas.ch 

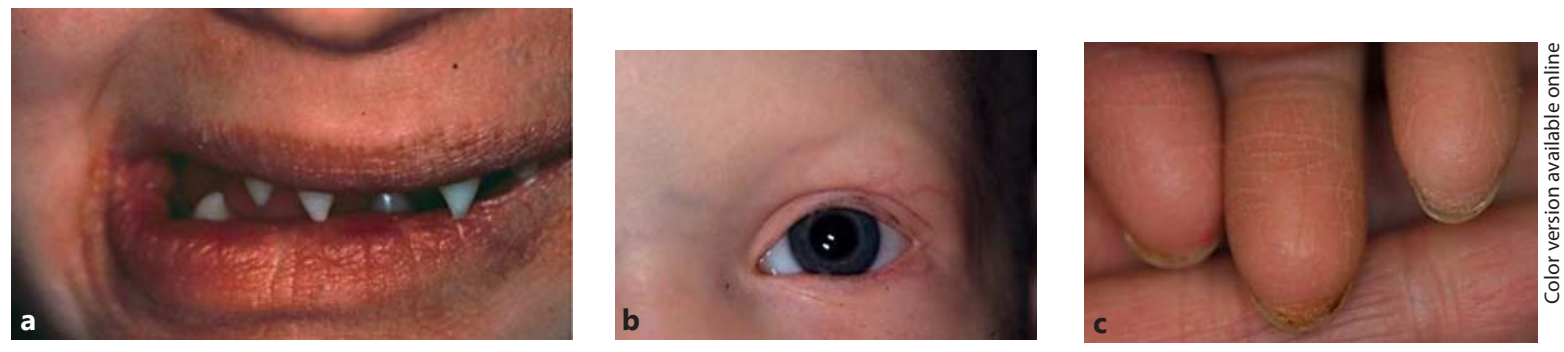

Fig. 1. a Typical malformed teeth in anhidrotic ectodermal dysplasia. b Almost absent eyebrows and cilia in different ectodermal dysplasias. c Rudimentary or absent finger ridges in several ectodermal syndromes. d Ectrodactylia in p63 mutation. e Fatty herniation in a patient with focal dermal hypoplasia.
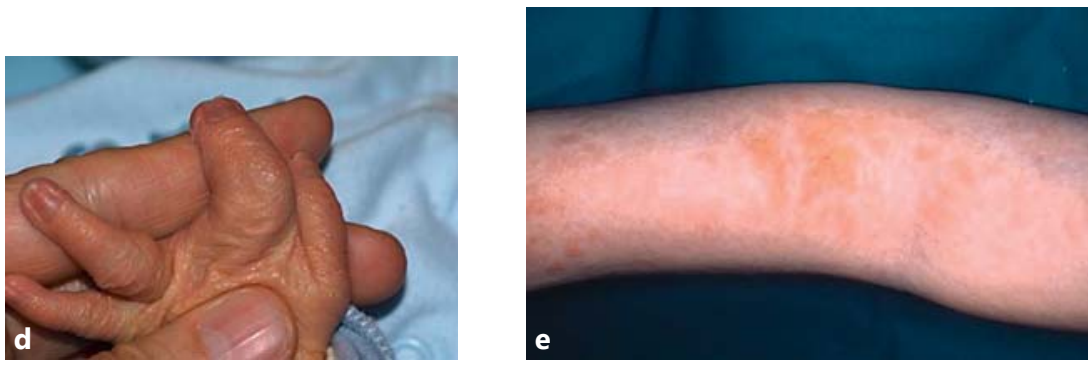

'omics revolution' and will lead to the detection of many new Mendelian disorders and their causative genes [7]. The 'interactome' distinguishes essential genes which lead to intrauterine abortion if missing, and nonessential genes which may lead to syndromal diseases. The new knowledge concerning biological networks in medicine has shown that even the phenotype in monogenic disorder is rarely a consequence of an abnormality in a single effector gene product, but reflects various pathobiological processes that interact in a complex network [8]. Disease pathways can be constructed according to topologically close genes or their products, functionally similar genes or their products and disease genes or their products [8].

Modern identification of disease gene candidates uses linkage methods, disease-module-based methods with clustering or graph-partitioning and diffusion-based methods. Recently, next-generation sequencing as a diagnostic tool in groups of syndromic diseases has used panels of several hundred genes which have been composed to identify disease-causing mutations in patients with syndromic epilepsy [9]. This has the advantage that the amount of data is restricted. A gene panel seems to be a fast and cost-efficient method to analyze the genetic basis, and could also be of help in ectodermal dysplasia. Indeed, only $10 \%$ of human genes have a known disease association.

In 1798, Willan proposed a method for the diagnosis of skin diseases and a nosology for cutaneous disorders [10]. In 1829, Alibert suggested a new concept of skin diseases by dividing them into twelve branches which he named the tree of dermatoses [11]. For him, the natural connections between the cutaneous efflorescences in the different skin diseases were important. In 1900, Brocq introduced the idea of the phenomenon of transfer between skin diseases, which meant that they are all somehow linked [11]. Classification of disease is an ongoing process that is influenced by clinical aspects, diagnostic skills and modalities, medical intervention, molecular understanding and community consensus [7]. Defining recognizable patterns of features and highlighting those that allow one condition to be distinguished from another (key features) includes the process of modern classification [12]. Unfortunately, such an approach has important shortcomings including a lack of sensitivity in identifying preclinical disease. Itin and Fistarol [1] also emphasized that, rather commonly, oligosymptomatic phenotypes exist in the spectrum of ectodermal dysplasias, which makes a clinical diagnosis more difficult. With the impressive molecular genetic progress and the increase of electronic databases, a new principal approach of classifying diseases has begun [13]. The combination of clinical key features (fig. 1a-d) and key molecular-signaling pathways will define the new classification scheme of ectodermal dysplasia. With the introduction of electronic health records, new potential arises for understanding genotype-phenotype relationships and for establishing new networks for unknown diseases. Modern possibilities evolve with the data-mining that occurs in such data sources combined with molecular genetic information [14]. 
All diseases are a result of the interaction between genetic constellations and environmental influences. Genome-transcriptome-proteome constellations and environmental perturbations lead to intermediate pathophenotypes and clinical syndromes and diseases [15]. This is why an understanding of the network context of a gene is essential in determining the phenotypic impact of the mutations and functional consequences that affect the phenotype [8]. Diseases originate from pathologies in organs comprised of different cells and biological structures with intracellular and intercellular molecular interactions. The human genome has about 30,000 genes. In 2007, 2,418 of these genes were associated with specific diseases. There made for an overlap of 1,777 disease-associated genes that were already known. The disease embryo development network reveals the relationship between disease genes and embryo development genes. An approach based on this network could document the important correlation between disease processes and embryo development, and aid in the understanding of the potential mechanisms of complex human diseases [16]. The term 'human interactome' has been created to describe this network medicine. However, there is a long way to go before a reliable network-based approach to disease is attained, because of the incompleteness of the available interactome maps at present and the limitations of the existing tools for exploring the pathogenetic relationships of diseases [8].

In my personal opinion, nowadays, the term ectodermal dysplasia is too broad and is not clearly reproducible. Most genetic skin disorders are somehow linked to the ectoderm, according to the development fields by Spemann, because the skin develops from ectoderm and mesoderm. Recognizing the complex network with the overlapping functions of the key genes that are responsible for the development of ectoderm, the term ectodermal dysplasia shifts more to the generalized term genodermatosis. This tendency is not helpful for general practice and should be corrected. A group of experts has compiled an extensive list (to which I have also contributed) of ectodermal diseases for the new ICD-11 classification, with the aim of providing clinicians with a list of those diseases which belong to ectodermal dysplasia. However, this list is incomplete and is not very systematic. Should cutaneous disorders with primary vascular malformations, dermal abnormalities or immunological disturbances be excluded? What about skin and bone diseases? In all these disease groups, there is much overlapping with clear ectodermal dysplasia such as mutation in the NEMO gene with immunodeficiency. Classification of ectodermal
Table 1. Criteria for ectodermal dysplasia entities

- The major clinical signs and symptoms affect the skin and/or its appendages

- They are persistent and not progressive

- The molecular mutation involves ectodermal key signaling pathways such as p63, ectodysplasin and WNT

- Molecular mutations lead to functional or structural changes in the ectoderm

- Regulators and coregulators of ectodermal genes are involved and are changed

dysplasia needs a consensus which will be consolidated within the next 12 months by a panel of experts. To define ectodermal dysplasia, clear, clinical features of a syndrome should be included, but molecular genetic aspects also have to be taken into account. For classifying ectodermal dysplasia, I suggest that the skin or its appendages should be the major clinical features presented (table 1). This is important, as several genes can have different mutations which can lead to totally variable phenotypes, some with primary skin problems and some with primary noncutaneous lesions [17]. As an additional criterium, the molecular defect should include one of the most important pathways for ectodermal developments or ectodermal key genes such as ectodysplasin, p63, WNT and their pathways. As ectodermal dysplasias can have life-long consequences, genetic analysis should be recommended for anticipating the prognostic factors of the disease, and could therefore be implicated in the classification recommendations. We are aware that not all countries have the costs of mutation analysis covered by insurance companies. In the near future, targeted sequence capture and high-throughput sequencing in the molecular diagnosis of a defined group of ectodermal dysplasias will become possible and this should be more affordable [18].

References

1 Itin PH, Fistarol SK: Ectodermal dysplasias. Am J Med Genet 2004;131C:45-51.

$\checkmark 2$ Yin $\mathrm{W}, \mathrm{Ye} X \mathrm{X}$, Bian Z: The second deletion mutation in exon 8 of EDA gene. Dermatology, in press.

3 Wisniewsky SA, Trzeciak WH: A new mutation resulting in the truncation of the TRAF6interacting domain of XEDAR: a possible novel cause of hypohidrotic ectodermal dysplasia. J Med Genet 2012;49:499-501. 
-4 Warman ML, Cormier-Daire V, Hall C, Krakow D, Lachman R, LeMerrer M, Mortier G, Mundlos S, Nishimura G, Rimoin DL, Robertson S, Savarirayan R, Sillence D, Spranger J, Unger S, Zabel B, Superti-Furga A: Nosology and classification of genetic skeletal disorders: 2010 revision. Am J Med Genet 2011; 155A:943-968.

$>5$ Isinoni AF, Isboa-Costa T, Agnan NA, Hautard-Freire-Maia EA: Ectodermal dysplasias: clinical and molecular review. Am J Med Genet 2009;149A:1980-2002.

6 Veltman JA, Brunner HG: De novo mutations in human genetic disease. Nat Rev Genet 2012;13:565-575.

7 Amberger J, Bocchini C, Hamosh A: A new face and new challenges for Online Mendelian Inheritance in Man $\left(\mathrm{OMIM}^{\circledR}\right)$. Hum Mutat 2011;32:564-567.

-8 Barabasi AL, Ulbahce N, Scalzo J: Network medicine: a network-based approach to human disease. Nat Rev Genet 2011;12:56-58.
9 Lemke JR, Riesch E, Scheurenbrand T, Schubach M, Wilhelm Ch, Steiner I, Hansen J, Courage C, Gallati S, Bürki S, Strozzi S, Goeggel Simonetti B, Grunt S, Steinlin M, Alber M, Wolff M, Klopstock T, Prott EC, Lorenz R, Spaich C, Rona S, Lakshminarasimhan M, Kröll J, Dorn T, Krämer G, Synofzik M, Becker F, Weber YG, Lerche H, Böhm D, Biskup $\mathrm{S}$ : Targeted next generation sequencing as a diagnostic tool in epileptic disorders. Epilepsia 2012;53:1387-1398.

10 Tilles G, Wallach D: Robert Willan and the French Willanists. Br J Dermatol 1999;140: 1122-1126.

-11 Tilles G, Wallach D: Histoire de la nosologie en dermatologie. Ann Dermatol Venereol 1989; 116:9-26.

12 DiGiovanna JJ, Priolo M, Itin P: Approach towards a new classification for ectodermal dysplasias: integration of the clinical and molecular knowledge. Am J Med Genet 2009; 149A:2068-2070.

13 Itin PH: Rationale and background as basis for a new classification of the ectodermal dysplasias. Am J Med Genet 2009;149A:19731976.

14 Jensen PB, Jensen LJ, Brunak S: Mining electronic health records: towards better research applications and clinical care. Nat Rev Genet 2012;13:395-405.
5 Loscalzo J, Kohane I, Barabasi AL: Human disease classification in the postgenomic era: a complex systems approach to human pathobiology. Mol Syst Biol 2007;3:124.

16 Gong B, Liu T, Zhang X, Chen X, Li J, Lv X, Zou Y, Li X, Rao S: Disease embryo development network reveals the relationship between disease genes and embryo development genes. J Theor Biol 2011;287:100-108.

17 Zarnegar BJ, Webster DE, Lopez-Pajares V, Vander Stoep Hunt B, Qu K, Yan KJ, Berk DR, Sen GL, Khavari PA: Genomic profiling of a human organotypic model of AEC syndrome reveals ZNF750 as an essential downstream target of mutant TP63. Am J Hum Genet 2012;91:435-443.

18 Scott CA, Plagnol V, Nitoiu D, Bland PJ, Blaydon DC, Chronnell CM, Poon DS, Bourn D, 1, Gardos L, Csaszar A, Tihanyi M, Rustin M, Burrwos NP, Bennett C, Harper JI, Conrad B, Verma IC, Taibjee SM, Moss C, O’Toole EA, Kelsell DP: Targeted sequence capture and high-throughput sequencing in the molecular diagnosis of ichthyosis and other skin diseases. J Invest Dermatol 2013;133:573-576. 